\title{
HUBUNGAN JUMLAH PEMERIKSAAN ANTENATAL DENGAN HASIL KEHAMILAN DAN PERSALINAN DI RSUP PROF. DR. R.D. KANDOU MANADO
}

\author{
${ }^{1}$ Janson Simanjuntak \\ ${ }^{2}$ Joice MM Sondakh \\ ${ }^{2}$ Freddy Wagey
}

\author{
${ }^{1}$ Skripsi Fakultas Kedokteran Universitas Sam Ratulangi Manado \\ ${ }^{2}$ Bagian Obstetri \& Ginekologi RSUP Prof.Dr.R.D. Kandou Manado \\ Email: simanjuntak.janson@yahoo.co.id
}

\begin{abstract}
Maternal and perinatal mortality rate in Indonesia is still high. The most cause of maternal and perinatal deaths related to pregnancy and complication of pregnancy can be prevented. Adequate antenatal care is an important factor in reducing maternal and perinatal deaths. This is an analytic observasional cross-sectional study of 2268 women delivered and 2305 neonates born at Prof.Dr.R.D.Kandou Manado hospital was used. Data is collected from medical record. This study shows that number of antenatal care $<4$ times is significantly associated with the incidence of severe asphyxia ( $p=0,003$; PR: 2,047; 95\% CI: 1,29-3,25) and low birth weight ( $\mathrm{p}=0,000$; PR: 1,713 ; $95 \% \mathrm{CI}$ : $1,32-2,23)$. The number of antenatal care $\geq 4$ times is significantly associated with operative delivery $(p=0,001)$, this is due to Prof.Dr.R.D.Kandou Manado hospital is a referral hospital in North Sulawesi, many samples in this study are women with complicated pregnancy (26,7\%). Pregnancy with complications is significantly related to operative delivery ( $\mathrm{p}=0,000$; PR: 1,$962 ; 95 \% \mathrm{CI}: 1,77-2,17$ ). Conclusion is number of antenatal care $<4$ times relates and increases the risk of incidence of asphyxia and low birth weight, while women with operative delivery are likely to have history of antenatal care visit more ( $\geq 4$ times) during pregnancy.
\end{abstract}

Keywords: antenatal care, delivery outcome, pregnancy outcome.

\begin{abstract}
Abstrak: Angka kematian ibu dan perinatal di Indonesia masih tinggi. Sebagian besar penyebab kematian ibu dan perinatal yang berhubungan dengan kehamilan dan komplikasi kehamilan dapat dicegah.Pemeriksaan antenatal yang adekuat merupakan faktor penting dalam menurunkan angka kematian ibu dan perinatal. Jenis penelitian ini adalah analitik observatif cross-sectionalterhadap 2268 ibu yang melahirkan di RSUP Prof.Dr.R.D.Kandou Manado dan 2305 bayi yang dilahirkan. Data diperoleh dari catatan medis.Hasil penelitian ini menunjukkan jumlah pemeriksaan antenatal $<4$ kali berhubungan dengan kejadian asfiksia berat ( $\mathrm{p}=0,003$; PR: 2,047; 95\% CI: 1,29-3,25) danBBLR ( $\mathrm{p}=0,000$; PR: 1,713; 95\% CI: 1,32$2,23)$. Jumlah pemeriksaan antenatal $\geq 4$ kali berhubungan dengan persalinan tindakan $(\mathrm{p}=0,001)$, hal ini disebabkan RSUP Prof.Dr.R.D.Kandou Manado merupakan rumah sakit rujukan di Sulawesi Utara sehingga banyak sampel pada penelitian ini adalah ibu-ibu dengan kehamilan dengan komplikasi (26,7\%). Kehamilan dengan komplikasi berhubungan dengan persalinan tindakan ( $\mathrm{p}=0,000$; PR: 1,962; 95\% CI: 1,77-2,17). Kesimpulan penelitian ini menunjukkan bahwa jumlah pemeriksaan antenatal $<4$ kali berhubungan dan meningkatkan risiko kejadian asfiksia berat dan BBLR, sementara itu wanita yang melakukan persalinan tindakan cenderung memiliki riwayat melakukan pemeriksaan antenatal lebih banyak ( $\geq 4$ kali) selama kehamilan.
\end{abstract}

Kata kunci:hasil kehamilan, hasil persalinan, pemeriksaan antenatal 
Angka kematian merupakan salah satu indikator status kesehatan masyarakat. WHO memperkirakan lebih dari 500.000 ibu mati tiap tahun karena kehamilan dan komplikasi yang berhubungan dengan kehamilan. 'Menurut data Survei Demografi dan Kesehatan Indonesia (SDKI) 2007, Angka Kematian Ibu (AKI) sebesar 228 per 100.000 kelahiran hidup. Angka ini masih tinggi, ditargetkan pada tahun 2015 (MDGs) angka kematian ibu di Indonesia turun menjadi 102 per 100.000 kelahiran hidup. ${ }^{2}$

Tujuh juta kematian perinatal pada negara berkembang berhubungan dengan masalah kesehatan ibu. Empat juta merupakan lahir mati (stillbirth) dan tiga juta merupakan kematian neonatal awal. Angka Kematian Neonatus di Indonesia menurut SDKI 2007 sebesar 19 per 1.000 kelahiran hidup. ${ }^{2}$

Ditemukan bahwa 88\% hingga 98\% dari semua kematian ibu dapat dicegah dengan penanganan yang tepat selama kehamilan dan persalinan.Pemeriksaan antenatal yang adekuat diketahui sebagai suatu faktor penting dalam menurunkan kematian ibu dan neonatus. ${ }^{1}$ Standar pemeriksaan antenatal di Indonesia adalah minimal 4 kali selama kehamilan. Namun, kenyataanya tidak semua ibu hamil melakukan pemeriksaan antenatal selama kehamilan, juga ada beberapa ibu hamil yang melakukan pemeriksaan antenatal $<4$ kali selama kehamilannya. ${ }^{2}$

Pada tahun 2010, cakupan pelayanan antenatal kunjungan pertama $\left(\mathrm{K}_{1}\right)$ di Indonesia sebesar 95,26\% dan sedangkan cakupan pelayanan antenatal hingga kunjungan keempat $\left(\mathrm{K}_{4}\right)$ sebesar 85,56\%. Pada tahun yang sama, di Sulawesi Utara cakupan $K_{1}$ sebesar 91,09\% sedangkan cakupan $\mathrm{K}_{4}$ sebesar $82,14 \%{ }^{2}$

Kualitas pelayanan antenatal di Indonesia masih rendah. Pada tahun 2008, cakupan $\mathrm{K}_{4}$ di Indonesia sebesar 86,04\%, namun hanya 48,14\% yang mendapatkan 90 tablet besi dan hanya 42,9\% yang mendapatkan suntikan TT dua kali. ${ }^{3}$ Presentase ibu hamil yang mendapatkan pelayanan 5T, yaitu ukur berat badan, tinggi badan, tekanan darah, pemberian imunisasi TT \& tablet $\mathrm{Fe}$, di Indonesia hanya sebesar $19,9 \%$ dan di Sulawesi Utara hanya sebesar $18,5 \%{ }^{4}$

Penelitian sebelumnya mengenai hubungan jumlah kunjungan antenatal dengan hasil kehamilan dan persalinan didapatkan hasil yang bertolak-belakang. Menurut Brown etal ${ }^{5}$ wanita dengan kunjungan antenatal dua kali memiliki hasil kehamilan dan persalinan yang lebih baik daripada wanita dengan kunjungan sebanyak tiga kali. Sebaliknya, menurut Taguchi et $\mathrm{al}^{6}$ jumlah kunjungan antenatal kurang dari 4 kali meningkatkan risiko kematian ibu.

\section{TUJUAN}

Penelitian ini bertujuan untuk mengetahui hubungan antara jumlah pemeriksaan antenatal dengan hasil kehamilan dan persalinan di RSUP Prof. Dr. R.D. Kandou Manado.

\section{METODE}

Suatu studi analitik observatifcrosssectional terhadap wanita yang melahirkan di RSUP Prof. Dr. R.D. Kandou Manado dan bayi yang dilahirkan periode bulan Januari 2012 hingga Juni 2012. Besar sampel adalah 2268 wanita yang melahirkan dan 2305 neonatus.Data didapatkan dari catatan medik. Data yang dikumpulkan adalah data pribadi, jumlah pemeriksaan antenatal, tekanan darah, kejadian perdarahan, penyakit infeksi pada data ibu, berat badan lahir, skor Apgar, kelainan kongenital, kematian perinatal pada data bayi, dan jenis persalinan. Data dianalisis dengan menggunakan program SPSS. Analisis bivariat menggunakan chisquare dengan $\alpha<0,05$.

\section{HASIL}

Data dari catatan medis di Bagian Obstetri dan Ginekologi RSUP Prof. dr. R.D. Kandou Manado dari bulan Januari 2012 sampai dengan bulan Juni 2012 tercatat sebanyak 2.268 orang ibu yang 
melahirkan. Ada 35 ibu dengan kehamilan gemeli dan 1 orang ibu dengan kehamilan triplet.Total 2.305 janin yang dilahirkan dengan sebanyak 2.291 persalinan.

Tabel 1. Distribusi sampel

\begin{tabular}{|c|c|c|c|}
\hline No & Kategori & $\mathbf{n}$ & (\%) \\
\hline \multirow[t]{4}{*}{1.} & Umur (tahun) & & \\
\hline & $<20$ & 296 & $(13,1)$ \\
\hline & $20-35$ & 1537 & $(67,8)$ \\
\hline & $>35$ & 404 & $(17,8)$ \\
\hline & Pendidikan & & \\
\hline & SD & 203 & (9) \\
\hline & SMP & 380 & $(16,7)$ \\
\hline & SMA & 1319 & $(58,2)$ \\
\hline & $\mathrm{PT}$ & 268 & $(11,8)$ \\
\hline \multirow[t]{3}{*}{3.} & Jumlah ANC & & \\
\hline & $<4$ & 356 & $(15,7)$ \\
\hline & $\geq 4$ & 1789 & $(77,1)$ \\
\hline \multicolumn{4}{|c|}{ 4. Hasil Ibu } \\
\hline & Tanpa Komplikasi & 1662 & $(73,3)$ \\
\hline & Dengan Komplikasi: & 606 & $(26,7)$ \\
\hline & - Hipertensi & 547 & $(90,3)$ \\
\hline & - Perdarahan & 77 & $(12,7)$ \\
\hline & - Infeksi & 5 & $(0,83)$ \\
\hline \multicolumn{4}{|c|}{ 5. Skor Apgar } \\
\hline & $0-3$ & 98 & $(4,3)$ \\
\hline & $4-6$ & 83 & $(3,6)$ \\
\hline & $7-10$ & 2086 & $(90,5)$ \\
\hline 6. & Kelainan Kongenital & 16 & $(0,69)$ \\
\hline & Kematian Perinatal: & & \\
\hline & - Lahir mati & 57 & $(2,47)$ \\
\hline & - KND & 12 & $(0,52)$ \\
\hline \multirow[t]{4}{*}{8.} & Berat badan lahir & & \\
\hline & $<2500$ & 288 & $(12,5)$ \\
\hline & $2500-<4000$ & 1929 & $(83,7)$ \\
\hline & $\geq 4000$ & 86 & $(3,7)$ \\
\hline & Jenis Persalinan & & \\
\hline & Spontan & 1451 & $(63,3)$ \\
\hline & Tindakan & 840 & $(36,7)$ \\
\hline
\end{tabular}

Hasil ibu dikategorikan menjadi ibu tanpa komplikasi dengan ibu dengan komplikasi.Komplikasi yang dinilai pada penelitian ini adalah perdarahan, hipertensi dan infeksi. Hasil analisis statistik menunjukkan tidak ada hubungan antara jumlah pemeriksaan antenatal $<4$ kali dengan kejadian perdarahan $(\mathrm{p}=0,874)$, hipertensi $(p=1,000)$ dan infeksi $(p=0,596)$. Walaupun tidak berhubungan secara bermakna, kejadian perdarahan lebih sering pada wanita dengan jumlah pemeriksaan antenatal $<4$ kali daripada pada wanita dengan jumlah pemeriksaan antenatal $\geq 4$ kali.

Hasil fetus dinilai berdasarkan skor Apgar, kematian perinatal, dan kelainan kongenital. Hasil analisis statistik menunjukkan jumlah pemeriksaan antenatal $<4$ kali berhubungan dengan kejadian asfiksia berat $(p=0,003)$, namun tidak berhubungan dengan kejadian asfiksia ringan sedang $(p=0,422)$. Wanita yang melakukan pemeriksaan antenatal $<4$ kali memiliki risiko 2,047 kali melahirkan janin dengan asfiksia berat $(\mathrm{PR}=2,047 ; 95 \% \mathrm{CI}$ $=1,29-3,25$ ). Jumlah kunjungan antenatal $<4$ kali tidak berhubungan dengan kematian perinatal $(\mathrm{p}=0,167)$ dan kelainan kongenital $(\mathrm{p}=0,169)$.

Hasil analisis statistik menunjukkan ada hubungan antara jumlah pemeriksaan antenatal $<4$ kali dengan berat badan lahir rendah $\quad(p=0,000)$, namun tidak berhubungan dengan berat badan lahir lebih. Wanita yang melakukan pemeriksaan antenatal $<4$ kali memiliki risiko 1,713 kali melahirkan janin dengan berat badan lahir jelek $(\mathrm{PR}=1,713 ; 95 \% \mathrm{CI}=1,32-2,23)$.

Jenis persalinan dikelompok-kan menjadi dua yakni persalinan spontan dan persalinan dengan tindakan. Hasil analisis statistik menunjukkan ada hubungan antara jumlah pemeriksaan antenatal $<4$ kali dengan persalinan dengan tindakan $(p=0,001)$. Ibu dengan jumlah pemeriksaan antenatal $<4$ kali lebih banyak melakukan persalinan spontan, sebaliknya ibu dengan jumlah pemeriksaan antenatal $\geq 4$ kali lebih banyak melakukan persalinan dengan tindakan. 
Tabel 2. Analisis Hubungan Jumlah Pemeriksaan Antenatal dengan Hasil Kehamilan \& Persalinan

\begin{tabular}{|c|c|c|c|c|c|c|c|}
\hline No & V. Terikat & Kategori & $<4(\%)$ & $\geq 4(\%)$ & PR & $95 \% \mathrm{CI}$ & $\mathbf{p}<\mathbf{0 , 0 5}$ \\
\hline \multirow{5}{*}{1} & \multirow{5}{*}{ Hasil Ibu } & Tanpa Komplikasi & $262(73,6)$ & $1279(73,1)$ & & & \\
\hline & & Dengan Komplikasi : & $94(26,4)$ & $470(26,9)$ & 0,983 & $0,81-1,19$ & 0,908 \\
\hline & & Perdarahan & $13(3,7)$ & $58(3,3)$ & 1,10 & $0,61-1,99$ & 0,874 \\
\hline & & Hipertensi & $85(26,3)$ & $424(26,3)$ & 1,002 & $0,82-1,22$ & 1,000 \\
\hline & & Infeksi & $0(0)$ & $5(0,3)$ & & & 0,596 \\
\hline \multirow{6}{*}{2} & \multirow{6}{*}{ Hasil Fetus } & Apgar Score & & & & & \\
\hline & & Asfiksia Berat (0-3) & $24(6,8)$ & $58(3,4)$ & 2,047 & $1,29-3,25$ & 0,003 \\
\hline & & $\begin{array}{c}\text { Asfiksia Ringan-Sedang } \\
\text { (4-6) }\end{array}$ & $15(4,3)$ & $58(3,4)$ & 1,314 & $0,75-2,29$ & 0,422 \\
\hline & & Bugar (7-10) & $313(88,9)$ & $1609(93,2)$ & & & \\
\hline & & Kematian Perinatal & $14(3,9)$ & $43(2,5)$ & 1,60 & $0,88-2,89$ & 0,167 \\
\hline & & Kelainan Kongenital & $5(1,4)$ & $11(0,6)$ & 2,23 & $0,78-6,39$ & 0,169 \\
\hline \multirow{3}{*}{3} & \multirow{3}{*}{$\begin{array}{l}\text { Berat Badan Lahir } \\
\text { (Kg) }\end{array}$} & Rendah $(<2,5)$ & $62(17,4)$ & $178(10,2)$ & 1,713 & $1,32-2,23$ & 0,000 \\
\hline & & Baik $(2,5-<4)$ & $280(78,7)$ & $1504(86)$ & & & \\
\hline & & Lebih $(\geq 4)$ & $14(3,9)$ & $66(3,8)$ & 1,13 & $0,65-1,99$ & 0,782 \\
\hline \multirow{2}{*}{4} & \multirow{2}{*}{ Jenis Persalinan } & Spontan & $259(73)$ & $1109(63,4)$ & 1,15 & $1,07-1,24$ & \multirow{2}{*}{0,001} \\
\hline & & Tindakan & $96(27)$ & $639(36,6)$ & 0,74 & $0,62-0,89$ & \\
\hline
\end{tabular}

Tabel 3. Hubungan hasil ibu dengan jenis persalinan

\begin{tabular}{ccccccc}
\hline V. Terikat & Kategori & Tanpa Komplikasi (\%) & Ada Komplikasi (\%) & PR & 95\% CI & p <0,05 \\
\hline Jenis & Spontan & $1158(70,4)$ & $249(42)$ & 1.962 & $1,77-2,17$ & 0,000 \\
Persalinan & Tindakan & $487(29,6)$ & $345(58)$ & & \\
\hline
\end{tabular}

\section{PEMBAHASAN}

Angka kematian merupakan salah satu indikator status kesehatan masyarakat. Pada penelitian ini didapatkan kejadian kematian perinatal di RSUP Prof.dr.R.D.Kandou Manado periode bulan Januari sampai dengan Juni 2012 sebesar 69 per 2305 kelahiran.

Kematian perinatal disebabkan oleh masalah kesehatan pada ibu.Pemeriksaan antenatal selama kehamilan terbukti menurunkan angka kematian perinatal. Standar pemeriksaan antenatal yang dianjurkan WHO dan direkomendasikan oleh Departemen Kesehatan adalah minimal 4 kali selama kehamilan. Penelitian ini mendapatkan bahwa dari 2268 ibu yang tercatat pada catatan medis, jumlah ibu yang melakukan kunjungan antenatal $\geq 4$ kali sebesar 77,1\%. Pada tahun 2010, cakupan $\mathrm{K}_{4}$ di Indonesia sebesar 85,56\%. Sementara itu, pada tahun yang sama di Sulawesi Utara cakupan $\mathrm{K}_{4}$ sebesar 82,14. ${ }^{2}$ Sehingga, pada penelitian ini didapatkan, cakupan $\mathrm{K}_{4}$ masih rendah ditambah dengan $15,7 \%$ ibu yang melakukan pemeriksaan antenatal $<4$ kali.

Penelitian sebelumnya menunjukkan bahwa kurangnya pemeriksaan antenatal berhubungan dengan skor Apgar yang rendah. ${ }^{7}$ Pernyataan tersebut sejalan dengan hasil yang didapat pada penelitian ini, yaitu terdapat hubungan antara jumlah pemeriksaan antenatal dengan skor Apgar. Hasil penelitian menunjukan skor Apgar 0-3 dan 4-6 lebih sering terjadi pada kelompok ibu dengan pemeriksaan antenatal <4 kali.Sebaliknya bayi dengan skor 7-10 lebih banyak pada kelompok ibu dengan pemeriksaan antenatal $\geq 4$ kali.Namun, pada analisis bivariat hanya skor Apgar 0-3 yang berhubungan signifikan dengan jumlah pemeriksan antenatal $<4$ kali.Hal ini menunjukkan bahwa jumlah pemeriksaan antenatal $\leq 4$ kali merupakan faktor risiko 
terjadinya asfiksia berat pada neonatus.Wanita dengan jumlah pemeriksaan antenatal $\leq 4$ kali memiliki risiko 2,047 kali melahirkan janin dengan asfiksia berat.

The American College of Obstetricians and Gynecologists dan the American Academy of Pediatrics menyatakan salah satu kriteria seorang neonatus dikatakan asfiksia jika skor Apgar 0-3 selama lebih dari 5 menit. Kelahiran asfiksia dapat disebabkan karena kejadian selama periode antepartum, intrapartum, atau postpartum maupun kombinasi diantaranya.Penelitian terbaru menyatakan asfiksia paling banyak disebabkan oleh kejadian selama periode antenatal. $^{8}$

Nayeri et $\mathrm{al}^{9}$ menyimpulkan bahwa persalinan seksio sesarea darurat, persalinan prematur ( $<37$ minggu), berat badan lahir kurang dari 2500 gram dan anemia neonatal merupakan faktor-faktor yang menyebabkan terjadinya asfiksia. Faktor-faktor tersebut dapat dicegah dengan perawatan/pemeriksaan antenatal yang baik.

Walaupun tidak berhubungan bermakna, bayi dengan skor Apgar 4-6 lebih banyak pada kelompok ibu dengan jumlah pemeriksaan antenatal kurang dari empat kali. Hal ini sejalan dengan hasil penelitian Pant et al $^{10}$ yang meneliti 91 bayi baru lahir untuk melihat hubungan antara pemeriksaan antenatal dengan skor Apgar bayi. Dari 50 bayi dengan skor Apgar 5-7 (asfiksia ringan-sedang) $80 \%$ berasal ibu yang tidak melakukan pemeriksaan antenatal dan 20\% dari ibu yang melakukan pemeriksaan antenatal.

Berat badan lahir rendah merupakan suatu indikator status kesehatan reproduksi dan kesehatan umum yang penting pada suatu populasi. BBLR prediktor tunggal paling penting terhadap kematian bayi, terutama kematian dalam bulan pertama kehidupan. Kematian neonatal 20 kali lebih banyak pada bayi dengan BBLR. ${ }^{11}$

Berat badan lahir rendah berhubungan kuat dengan pemeriksaan antenatal yang tidak adekuat $\left(<4\right.$ kali). ${ }^{12}$ Pemeriksaan antenatal dapat memperbaiki berat bagan lahir melalui pencegahan kejadian kecil untuk masa kehamilan (KMK), nutrisi yang lebih baik selama kehamilan dan penurunan kebiasaan merokok. ${ }^{11,13}$

Pada penelitian ini didapatkan bahwa jumlah pemeriksan antenatal berhubungan dengan berat badan lahir.Hasil penelitian menunjukkan berat badan lahir rendah lebih banyak terjadi pada bayi dari ibu yang melakukan pemeriksaan antenatal <4 kali.Hal ini sesuai dengan hasil penelitian Deshpande et al. Ibu dengan pemeriksaan antenatal $<4$ kali selama kehamilan memiliki risiko 1,713 kali melahirkan bayi dengan berat badan lahir rendah.

Etiologi kejadian berat badan lahir rendah adalah multifakor.Perhatian khusus dari tenaga kesehatan professional dibutuhkan untuk mengidentifikasi faktorfaktor risiko terjadinya berat badan lahir rendah. Pemeriksaan antenatal memberikan kesempatan bagi ibu hamil untuk melakukan konseling dan deteksi risikorisiko yang mungkin ada. ${ }^{12,14}$

Pemeriksaan antenatal digunakan untuk memantau perkembangan kehamilan ibu, frekuensi minimal 4 kali selama kehamilan. Pemeriksaan antenatal yang teratur akan memberikan kesempatan untuk dapat mendiagnosis secara dini adanya ketidaknormalan atau komplikasi yang mungkin terjadi pada ibu dan janin selama kehamilan sehingga dapat dilakukan tindakan yang tepat secepatnya. ${ }^{15}$

Pada penelitian ini jenis persalinan dikelompokkan menjadi duayakni persalinan spontan dan persalinan dengan tindakan. Hasil penelitian menunjukkan bahwa jumlah pemeriksaan antenatal berhubungan dengan jenis persalinan. Persalinan spontan lebih banyak terjadi pada kelompok ibu dengan pemeriksaan antenatal <4 kali. Sebaliknya persalinan tindakan lebih banyak terjadi pada ibu dengan pemeriksaan antenatal $\geq 4$ kali.

Jenis persalinan yang dilakukan dapat dipengaruhi oleh keinginan ibu. Namun disisi lain, adanya faktor-faktor risiko tertentu juga dapat menentukan dilakukannya persalinan dengan tindakan, seperti usia ibu lebih dari 35 tahun $(\geq 35)$, ibu dengan anemia, ibu dengan tekanan darah tinggi, karena kondisi kesehatan umum akan sangat 
mempengaruhi kondisi kehamilan dan proses persalinan. Adanya keluhan selama kehamilan merupakan faktor risiko terjadinya komplikasi persalinan yang akhir-nya terjadi persalinan dengan tindakan. ${ }^{16}$

RSUP Prof.Dr.R.D.Kandou Manado merupakan rumah sakit rujukan di Sulawesi Utara. Sehingga kasus-kasus kehamilan berisiko akan banyak ditemukan pada rumah sakit ini, pada penelitian ini diketahui selama bulan Januari 2012 hingga Juni 2012 terdapat 606 (26,7\%) ibu hamil dengan komplikasi hipertensi, perdarahan dan infeksi, yang termasuk dalam kelompok ibu dengan kehamilan berisiko. Tabel 3 menunjukkan adanya hubungan yang bermakna antara kehamilan dengan risiko dengan persalinan tindakan, dengan risiko sebesar 1,962 kali. Sehingga kehamilan dengan komplikasi meningkatkan risiko untuk persalinan dengan tindakan.

Jika seorang wanita telah mengetahui memiliki risiko-risko tertentu terjadinya penyulit-penyulit selama kehamilan dan persalinan, maka wanita tersebut akan lebih sering melakukan pemeriksaan akan kesehatan kehamilannya. Hal ini sejalan dengan hasil penelitian Brown et al $^{5}$ dimana adanya kecenderungan wanita untuk melakukan pemeriksaan antenatal lebih sering jika mereka memiliki masalah pada kehamilannya.

\section{SIMPULAN}

Jumlah pemeriksaan antenatal $<4$ kali selama kehamilan berhubungan dengan kejadian asfiksia berat dan berat badan lahir rendah. Kehamilan dengan komplikasi berhubungan dengan persalinan tindakan. Wanita dengan persalinan tindakan memiliki riwayat pemeriksaan antenatal $\geq 4$ kali.

\section{UCAPAN TERIMA KASIH}

Terima kasih kepada dr. R.A. Lengkong, SpOG-K dan dr. Maria Loho, SpOG-K yang telah memberikan perbaikan penulisan artikel ini, serta semua pihak yang telah membantu secara langsung maupun tidak langsung sehingga lahirnya ide penelitian ini.

\section{DAFTAR PUSTAKA}

1. Ziyo FY, Matly FA, Mehemd GM, Dofany EM. Relation between prenatal care and pregnancy outcome at Benghazi. Sudanese Journal of Public Health. 2009;4:403-10.

2. Kementerian Kesehatan Pusat Data dan Informasi. Profil kesehatan Indonesia 2010. Jakarta: Kementerian Kesehatan RI; 2011.

3. Departemen Kesehatan. Pusat Data dan Informasi. Profil kesehatan Indonesia 2008. Jakarta: Departemen Kesehatan RI; 2009.

4. Kemenkes RI. Riset kesehatan dasar (RISKESDAS) 2010. Jakarta: Badan Penelitian dan Pengembangan Kesehatan RI; 2010. h. 223,229.

5. Brown CA, Sohani SB, Khan K, Lilford R, Mukhwana W. Antenatal care and perinatal outcomes in Kwale district Kenya. BMC Pregnancy and Childbirth. 2008;8:111.

6. Taguchi N, Kawabata M, Maekawa $M$, Maruo T, Aditiwarman, Dewata $L$. Influence of socio-economic background and antenatal care programmes on maternal mortality in Surabaya, Indonesia. Trop Med Int Health. 2003;8:847-52.

7. Salusatiano EMA, Campos JADB, Ibidi SM, Ruano R, Zugaib M. Low apgar scores at 5 minutes in a low risk population: maternal and obstetrical factors and postnatal outcome. Rev Assoc Med Bras. 2012;58:587-93.

8. Haider BA, Bhutta ZA. Birth asphyxia in developing countries: current status and public health implications. Curr Probl Pediatr Adolesc Health Care. 2006;36:180.

9. Nayeri $F$, Shariat $M$, Dalili $H$, Adam LB, Mehrjerdi FZ, Shakeri A. Perinatal risk factors for neonatal asphyxia in Valie-Asr hospital, Tehran-Iran. Iran J Reprod Med. 2012;10:137-40.

10. Pant B, Kumar S, Davey A, Tiwari R. Antenatal care and pregnancy outcome. Indian J. Prev. Soc. Med. 2008;39:131.

11. Ganjoei TA, Mirzaei F, Dokht FA. Relationship between prenatal care and the outcome of pregnancy in low-risk pregnancies. Open Journal of Obstetrics and Gynecology. 2011;1:112.

12. Deshpande JD, Phalke DB, Bangal VB, Peeyuusha D, Sushen B. Maternal risk 
factors for low birth weight neonates: a hospital based case-control study in rural area of western Maharashtra, India. National Journal of Community Medicine. 2011;2:394-8.

13. Niclasen B. Low birthweight as an indicator of child health in Greenland-use, knowledge and implication. Int $\mathrm{J}$ Circumpolar Health [serial online]. 2007 [diakses tanggal 19 Desember 2012];66:223. Tersedia di: http://www. ncbi.nlm.nih.gov/pubmed/17655062.

14. Kadapatti MG, Vijayalaxmi AHM.
Antenatal care the essence of newborn weight and infant development. International Journal of Scientific and Research Publication. 2012;2:3.

15. Budiman, Riyanto A, Juhaeriah J, Gina H. Faktor ibu yang berhubungan dengan berat badan lahir di Puskesmas Garuda tahun 2010. Jurnal Kesehatan Kartika. 2011:1.

16. Kowalcek I, Hainer $\mathbf{F}$. Is there a relation between maternal age and preferred mode of delivery? Journal of Clinical Gynecology and Obstetrics. 2012;1:4-9. 